\title{
The retention of ACCESS nursing assistant graduates in rural Uganda
}

\author{
Mitra Sadigh*1, Jamie Sarfeh², Robert Kalyesubula ${ }^{3,4}$ \\ ${ }^{1}$ University of Vermont, Burlington, VT, United States \\ ${ }^{2}$ Brown University, Providence, Rhode Island, United States \\ ${ }^{3}$ Makerere University College of Health Sciences, Kampala, Uganda \\ ${ }^{4}$ The African Community Center for Social Sustainability (ACCESS), Nakaseke, Uganda
}

Received: August 7, 2017

DOI: $10.5430 /$ jnep.v8n1p94
Accepted: September 3, $2017 \quad$ Online Published: September 22, 2017

URL: https://doi.org/10.5430/jnep.v8n1p94

\begin{abstract}
Background: In 2004, the African Community Center for Social Sustainability (ACCESS) established a Nursing Assistant School in Nakaseke, a rural district in Uganda, to address the region's severe shortage of healthcare resources. A survey conducted in July 2014 assessed the retention of its graduates in rural healthcare work.

Methods: A survey aimed at evaluating the retention of ACCESS graduates in rural areas was created with the help of local stakeholders, focusing on demographics, the training program, employment, career development goals, and community impact. A short-form telephone survey was administered to graduates living outside Nakaseke, and a long-form in-person survey to graduates residing close to the school. Quantitative data was analyzed using standard statistical software, and qualitative data via identification of common themes.

Results: Thirty-seven participants were contacted using telephone numbers stored in a database containing information for 109 graduates. The mean participant age was 24 years, and $86.5 \%$ were female. Nearly all worked in healthcare $(91.1 \%)$, primarily in health clinics $(37.14 \%)$ and pharmacies $(33.33 \%)$ in communities they described as rural (80\%), low-resource (60\%), and underserved (25.7\%). Most graduates planned to continue working in healthcare $(85.3 \%)$ in rural areas $(61.3 \%)$. All felt that their work positively impacts their community.

Conclusions: The ACCESS nursing assistant training program provided a stepping stone for trainees while contributing to increased health service provision to the community. Rural-focused location and school curriculum, along with confidence building, may help retain nursing assistant trainees in underserved areas.
\end{abstract}

Key Words: Nursing education, Qualitative research, Rural retention

\section{BACKGROUND}

There is a shortage of healthcare workers (HCWs) in rural areas around the globe. ${ }^{[1]}$ This inequitable distribution of HCWs obstructs fair and equal access to health services, and further exacerbates the poor health status of people living in these areas as a result of poverty, malnutrition, and poor sanitation. ${ }^{[2]}$ In Uganda, seventy percent of doctors prac- tice in urban settings, with the doctor population ratio more favorable by a factor of seventeen in urban versus rural settings. ${ }^{[3]}$ Given this deficit of HCWs where they are needed most, methods of retaining HCWs in rural areas has been a prevalent and pivotal subject of research.

Numerous studies have investigated the efficacy of specific

*Correspondence: Mitra Sadigh; Email: mitrasadigh@gmail.com; Address: University of Vermont, Burlington, VT, United States. 
health education programs in the retention of HCWs in rural communities, ${ }^{[4]}$ while others have assessed the efficacy of interventions aimed at increasing the proportion of HCWs in rural and underserved areas. ${ }^{[5]}$ One study investigated the influence of the training experience of Makerere University medical and nursing graduates in Kampala, Uganda on their willingness to work in rural health facilities. ${ }^{[6]}$ It has been posited that HCWs trained in rural areas are more likely to remain and work in rural areas than their urban-trained counterparts, ${ }^{[7]}$ rendering such training a means of reducing the shortage of HCWs in rural areas.

Nakaseke is a recently formed rural district in Uganda with a population of $197,703,80 \%$ of whom live in rural areas. ${ }^{[8]}$ The district has a severe shortage of skilled HCWs with one doctor per 25,000 people compared to 1 per 390 in the U.S. and one nurse per 5,000 compared to 1 nurse per 110 people in the U.S. ${ }^{[9,10]}$ According to the district annual report of 2014 , only $58 \%$ of HCWs are formally trained and $57 \%$ of the parishes are without healthcare facilities. In 2004, the African Community Center for Social Sustainability (ACCESS) established a nursing assistant school in Nakaseke to help address this severe shortage of healthcare resources in the region. The training program began as an apprenticeship program before it was formalized with a one-year curriculum consisting of class work modules and clinical placements in government-owned health facilities. A survey study was conducted over a five-day period in July 2014 to assess the efficacy of the ACCESS training program in retaining HCWs in the rural areas in which they were trained.

\section{MethodS}

\subsection{Objective}

The objective of this study was to evaluate the outcomes of the ACCESS nursing assistant program graduates, with focus on demographics, post-training employment, community impact, and career development goals. The overall aim was to ascertain the efficacy of the program in retaining HCWs in rural areas where they are needed most.

\subsection{Study design}

A survey was created consisting of fifteen multiple-choice questions focused on demographics, pre-training status, the training process, post-training employment, community impact, and career development goals of ACCESS graduates. It was divided into two components: a long-form in-person survey and a short-form telephone survey. The first ten interviews were carefully reviewed for validity and efficacy of the survey instrument, after which modifications were made to create a revised form.

Published by Sciedu Press

\subsection{Survey administering}

The study was conducted in Nakaseke District, Uganda over a period of five days in late July 2014. In-person interviews were scheduled via telephone with those graduates residing near Nakaseke District. The researchers travelled to meeting sites, mainly at the current work places of ACCESS graduates, to administer the survey. Participants completed the survey one-on-one with a researcher after providing verbal consent. Open-ended responses were transcribed, and all responses were entered into a survey database. To provide visual documentation at the conclusion of the survey, photographs were taken of participants who gave verbal consent.

The short-form survey was administered to participants via telephone by volunteers fluent in both Luganda and English to help ease communication barriers. Participants gave verbal consent over the phone, and no photographs were taken. In the case that the phone number no longer belonged to the ACCESS student, the contact information was acquired from friends, former classmates, or family members when possible.

\subsection{Participant selection and sample size}

Participants were selected from a database containing the telephone contact information for 109 graduates. All provided contact information was utilized, however only 37 graduates were reached. There were no limitations to participating in the survey other than being graduates of ACCESS Nursing Assistant School, being contactable, and giving informed consent. Prior to administration of the questionnaire, whether in person or over the telephone, consent was explained orally and participants were given the option to opt-out from any parts and/or all of the survey.

\subsection{Data analysis}

Survey responses were recorded directly into a database created prior to study conduction. Because the study was descriptive and qualitative, no specific inferential statistical analysis was performed. Descriptive statistics were utilized by means of standard statistical software. Responses to open-ended portions of the survey, along with additional comments, were recorded and analyzed for identification of common themes.

\subsection{Results}

Thirty seven of the 109 for whom we had contact information were surveyed for this study. Not all 37 participants answered all of the questions. To account for this variation in sample size, the number of respondents to each respective question has been specified.Twenty-six $(70.3 \%)$ of the surveys were conducted via telephone, and $11(29.7 \%)$ in person. The majority of participants $32(86.5 \%)$ were female. 
Table 1. Responses of study participants

\begin{tabular}{|c|c|}
\hline & Total n (\%) \\
\hline \multicolumn{2}{|c|}{ Residence Following training $(\mathrm{N}=37)$} \\
\hline Nakaseke & 29.7 \\
\hline Luweero & 18.9 \\
\hline Other Districts & 51.4 \\
\hline \multicolumn{2}{|c|}{ Vocation of Graduates $(\mathrm{N}=37)$} \\
\hline Healthcare & 91.9 \\
\hline Not in Healthcare & 5.4 \\
\hline Studying Health & 2.7 \\
\hline \multicolumn{2}{|c|}{ Work Location of Graduates working in Healthcare* $(\mathrm{N}=34)$} \\
\hline Clinics & 37.14 \\
\hline Pharmacies/Drug Shops & 33.33 \\
\hline Private Hospitals & 14.28 \\
\hline Public Hospitals & 11.42 \\
\hline Students & 5.71 \\
\hline Others & 11.4 \\
\hline \multicolumn{2}{|l|}{ Area of Service $(\mathrm{N}=35)$} \\
\hline Rural & 82.35 \\
\hline Urban & 17.14 \\
\hline \multicolumn{2}{|l|}{ Patient follow up $(\mathrm{N}=34)$} \\
\hline Often & 32.4 \\
\hline Sometimes & 58.8 \\
\hline Rarely & 8.8 \\
\hline \multicolumn{2}{|c|}{ Average no. of patients served/week $(\mathrm{N}=35)$} \\
\hline$>100$ & 17.1 \\
\hline $70-99$ & 22.9 \\
\hline $30-70$ & 34.3 \\
\hline $1-30$ & 25.7 \\
\hline \multicolumn{2}{|c|}{ Financial stability after school $(\mathrm{N}=35)$} \\
\hline Fully stable & 11.42 \\
\hline Somewhat stable & 42.85 \\
\hline Not stable & 45.71 \\
\hline \multicolumn{2}{|c|}{ Major reason for career in Healthcare $(\mathrm{N}=37)$} \\
\hline Community service & 45.9 \\
\hline Interest in Health & 43.2 \\
\hline Financial interest & 5.4 \\
\hline Relatives’ influence & 5.4 \\
\hline \multicolumn{2}{|c|}{ Impact of trainees on community** $(\mathrm{N}=34)$} \\
\hline Significant impact & 52.9 \\
\hline Some impact & 47.1 \\
\hline \multicolumn{2}{|c|}{ Confidence providing healthcare $(\mathrm{N}=35)$} \\
\hline Confident & 80.0 \\
\hline Somewhat Confident & 14.3 \\
\hline Not Confident & 5.7 \\
\hline \multicolumn{2}{|c|}{ Plan to pursue further training $(\mathrm{N}=34)$} \\
\hline Yes & 80 \\
\hline Unsure & 17.14 \\
\hline No & 2.85 \\
\hline \multicolumn{2}{|c|}{ Plan to continue work in rural area $(\mathrm{N}=34)$} \\
\hline Yes & 61.3 \\
\hline Unsure & 25.8 \\
\hline No & 12.9 \\
\hline
\end{tabular}

\section{Discussion}

Given the need for healthcare workers in rural areas around the world, their retention in these areas is of great interest. According to a 2010 report of global policy recommendations for the rural retention of healthcare workers released by the World Health Organization, ${ }^{[7]}$ establishing clinical rotations in rural areas, creating curricula that reflect rural health issues, and providing continuous professional development for rural healthcare workers are educational interventions that affect the retention of healthcare workers in rural areas.

While there is abundant literature regarding methods of retention, there are few published case studies such as this one. However, in a 2008 study conducted in Mali, $85 \%$ of community doctors remained in rural areas during the period 2003-2007 following a specially designed orientation course for young practicing rural doctors. ${ }^{[1]}$ The study results suggest that increased self confidence and self esteem of rural practitioners as a result of the training may have contributed to their retention in rural areas, along with a sense of belonging to a professional group sharing a common professional identity.

Although majority of surveyed ACCESS graduates worked in rural areas and planned to continue to do so, it is not possible to determine a direct connection between their retention in rural areas and their training at ACCESS. Because other factors may have influenced their work location, such as their place of origin, the residence of their family members, and job availability, it is difficult to establish the impact of training graduates in rural areas and community-based care. Future studies can inquire further into the reasons graduate decide to remain in, or leave, rural areas.

However, some conjectures can be attempted. Firstly, the educational interventions for the rural retention of healthcare workers listed by the WHO are integral components of the ACCESS training program. These factors may have contributed to graduates' decision to stay in rural areas. Secondly, the high level of confidence most graduates felt in providing healthcare, which many attributed to the training program, may also have impacted this decision. It is likely that more robust opportunities for continuous professional development would help enhance the rural retention of ACCESS graduates, along with greater financial sustainability, although the latter is a factor that extends beyond the capacity of ACCESS.

Whereas ACCESS is located in rural Uganda, lessons learned from its training program and graduates can be applied to the establishment of healthcare training institutions in rural areas around the world. Moreover, the lessons learned through its implementation can benefit young researchers interested in fieldwork in resource-limited settings.

\section{Study limitations}

Difficulty contacting graduates for participation in the survey presented a major limitation. Many listed phone numbers 
were out of service, disconnected, or changed. Twenty-three provided phone numbers were contact numbers of students' parents, while some contact numbers were redundant. As a result, the study had only a convenient sample. Furthermore, the sample size of 37 graduates was rendered even smaller, as many graduates opted not to respond to some of the questions. However, despite the small, nonrandomized study sample, it is clear that the ACCESS nursing assistant training program provided a stepping-stone for trainees and impacted increased health service provision to the community.

While these limitations presented major unexpected obstacles to study conduction, they provided important learning points for young researchers interested in fieldwork in a resourcelimited setting. These lessons can be applied to fieldwork in any such setting. Because young people in Uganda are very mobile, it can be difficult to keep track of their whereabouts. Email contact is not as effective a means of communication as it is in the United States, as internet access is often intermittent. Furthermore, mobile lines commonly change, are multiple to each individual, and are shared with family members. Landlines, meanwhile, are uncommon. For all these reasons stated, it is challenging to maintain an up-to-date catalogue of information for all ACCESS graduates.

\section{Conclusion}

The study results revealed that majority of ACCESS graduates were female, and lived and worked in rural areas, mostly in Nakaseke and Luwero Districts near the ACCESS training site in communities they described as rural and low-resource. Almost all were employed in healthcare or were continuing their education in the field. Most graduates planned to continue working in healthcare and pursue further healthcare training and higher certification. Sixty-one-point three percent planned to continue working in rural areas.

All graduates felt that their work helped engender improvement in community awareness and disease prevention through providing services, encouraging use of health services by community members, or providing health education. While most graduates had not completed further training following graduation, those who had did so in nursing, midwifery, lab services, and malaria management. While graduates chose to work in healthcare for a variety of reasons, most were drawn to the field by a desire to help serve their community and general interest in healthcare. Many were involved in teaching community health education.

\section{ACKNOWLEDgements}

The authors would like to thank Erin Shaw, Registered Nurse Care Manager at Care Oregon in Portland, OR, and Executive Director of Partners for ACCESS for her valuable comments pertaining to the manuscript.

\section{CONFlicts of INTEREST Disclosure}

The authors declare no conflicts of interest.

\section{REFERENCES}

[1] Grobler L, Marais BJ, Mabunda SA, et al. Interventions for Increasing the Proportion of Health Professionals Practising in Rural and Other Underserved Areas. Wiley Online Library: The Cochrane Library. John Wiley \& Sons, Inc., 21 Jan. 2009.

[2] Boulle A. Rural healthcare and Rural Poverty - Inextricably Linked Policy in Progress. Health Systems Trust Update. 1997; 28: 6-7.

[3] Human Resources for Health Country Profile: Uganda. (2009, October 1). Available from: http://www.hrh-observatory.a fro.who.int/images/Document_Centre/uganda_country_ profile.pdf?ua1 Accessed February 1, 2017.

[4] Rabinowitz HK, Paynter NP. The role of the medical school in rural graduate medical education: pipeline or control valve? The Journal of Rural Health. 2000; 16: 249-53.

[5] Grobler L, Marais BJ, Mabunda SA, et al. Interventions for increasing the proportion of health professionals practising in rural and other underserved areas. The Cochrane Database of Systematic Reviews. 2009; 1(1): CD005314.

[6] Kaye DK, Mwanika A, Sewankambo N. Influence of the training experience of Makerere University medical and nursing graduates on willingness and competence to work in rural health facilities. Rural and Remote Health. 2010; 10(1): 1372.
[7] Increasing access to health workers in remote and rural areas through improved retention: Global policy recommendations. World Health Organization. Available from: http://www. searo. who. int/ne $\mathrm{pal} /$ mediacentre/2010_increasing_access_to_health_w orkers_in_remote_and_rural_areas.pdf Accessed June 1, 2017.

[8] Census 2014 Final Results. Uganda Bureau of Statistics. Available from: http://www.ubos.org/2016/03/24/census-2014-fin al-results/ Accessed June 1, 2017.

[9] Orphan Advocacy: The Genesis of ACCESS. Available from: https://www.uvm.edu/medicine/documents/CMS_Kal yesubula_Handout_040516.pdf Accessed June 1, 2017.

[10] The Nursing Workforce 2014: Growth, Salaries, Education, Demographics \& Trends. American Nurses Association. Available from: http://www.nursingworld.org/MainMenuCategorie $\mathrm{s} /$ ThePracticeofProfessionalNursing/workforce/Fas t-Facts-2014-Nursing-Workforce.pdf Accessed June 1, 2017.

[11] Van Dormael M, Dugas S, Kone Y, et al. Appropriate training and retention of community doctors in rural areas: a case study from Mali. Human Resources for Health. 2008; 6: 25. 